\title{
The application of natural dyes in Dye-sensitized solar cells
}

\author{
Junyi Yin ${ }^{1, a}$ \\ ${ }^{1}$ North China Electric Power University, Baoding 071003, China; \\ a2807129564@qq.com
}

Keywords: Natural dyes, Dye sensitized solar cell, Sensitizer

\begin{abstract}
Dye sensitizer is an important factor to the performance of dye sensitized solar cell (DSSC). This article simply reviews the development of dye-sensitized solar cells and the disadvantages of it at present, analyzes the advantages and disadvantages and its potential development of the natural dyes as dye-sensitized solar cells. According to the kinds of natural dyes used in recent years, this paper reviewed the research progress of natural dye-sensitized cells in detail, and then analysis and forecasts the development trend of natural dye-sensitized solar cells and the key problem must be solved to its practice.
\end{abstract}

\section{Introduction}

The history of the research of Dye sensitized Solar Cell can be traced back to the $1960 \mathrm{~s}$, because of the photoelectric conversion efficiency has been very low, so the early research work was not seriously viewed by people. Until 1991, professor Brian O 'Regan and professor Michael Grätzel[1] in EPFL reported in the journal Nature of dye-sensitized cells photoelectric conversion efficiency reached $7.1 \%$, and the cost is low, which caused the attention of the world. After more than ten years, scientists have done a lot of research in the operation mechanism of the battery and battery components optimization improvement, etc [2], making the DSSC gets rapid and steady development. Dye is one of the core parts of DSSC, whose function is to absorb sunlight, optoelectronics, and transmits photoelectron to the conduction band of $\mathrm{TiO}_{2}$. Therefore, the advantages and disadvantages of the performance of dye sensitizer play a decisive role to photoelectric conversion efficiency of the entire unit [3].

Natural dyes as a sensitizer in DSSC have attracted the attention of scientists at the beginning of the study, since the DSSC is designed according to nature of photosynthesis principle [4]. Natural dyes contain carboxyl, hydroxyl and so on which can easily react with the surface of nano $\mathrm{TiO}_{2}$. Natural dyes can be directly extracted from plants, with no pollution, no tedious synthesis, and separation and purification process is relatively simple. It could be achieved by a variety of natural dye sensitization to absorb sunlight all band range [5]. Recent decades, people has carried out extensive research in the natural dye sensitized DSSC.

With the development of the economy, environmental pollution and energy shortage problem are more and more serious, natural dye-sensitized solar cells as a form of solar energy utilization is high efficient and environmentally friendly cleaning, its research, development and utilization will attract more and more extensively attention. In this paper, the latest progress of the dye-sensitized cells in recent years are summarized, and tries to point out problems urgently to be solved in a variety of key materials and its development trend.

\section{Structure and working principle of dye-sensitized solar cells}

Dye sensitized solar cell is a "sandwich" structure which is made of transparent conductive glass, porous nanometer $\mathrm{TiO}_{2}$ membrane, electrolyte solution and platinum plating mirror of electrode structure. The photoelectric conversion complete in several interfaces: (1) interface of dye and $\mathrm{TiO}_{2}$ crystal porous membrane; (2) interface of the dye molecules and electrolyte; (3) interface of the electrolyte and the electrode. 
Photoelectric conversion mechanism is shown in Fig. 1, the physical and chemical process is as follows: (1) the sun to the battery, the ground state dye molecules which absorb sunlight energy is emitted, electron stimulated transition to the excited states of the dye molecules, dye molecules lost electronic and turn to oxidation state; (2) the excited states of electronic quickly inject into $\mathrm{TiO}_{2}$ conduction band; (3) electronic transfer very quickly in the $\mathrm{TiO}_{2}$ membrane, the progress to reach contact surface of membrane and conductive glass can be instantaneous and then electronic enrich on a conductive substrate, through the external flow of electrode; (4) at the same time, dye molecules which is in oxidation state, get electronic provided by electrolyte solution of the electron donor and returned to the ground; (5) after provide electronic in the electrolyte solution, electron donor spread to the electrode, where it can get electronics and reduction. Thus, DSSC completes a photoelectric chemical reaction cycle; also makes the battery components back to the initial state.

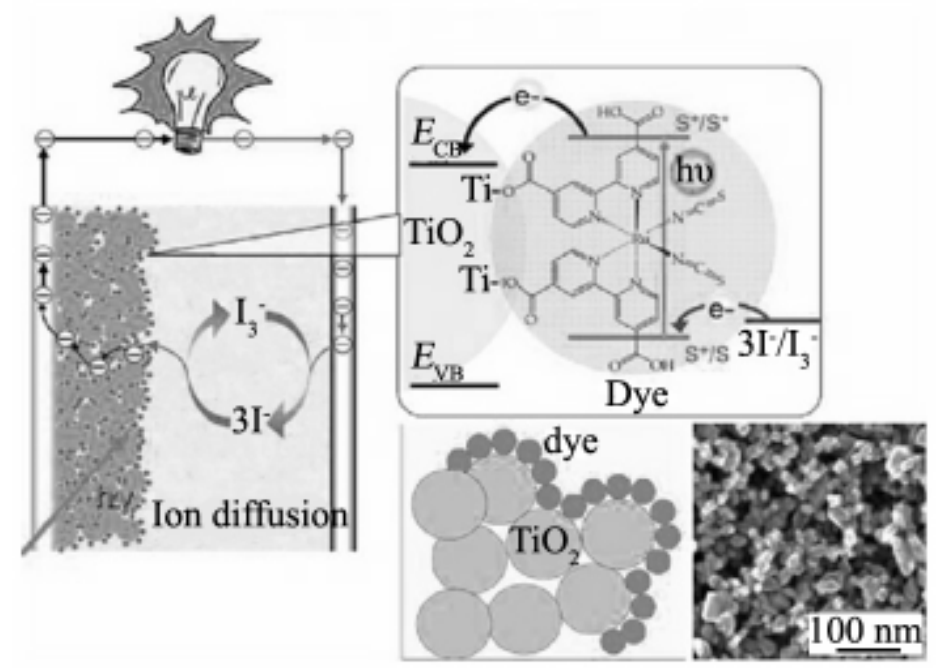

Fig. 1 Structure and operational principle of DSSC

Compared with the traditional solar cells, the biggest difference of Dye-sensitized solar cells is the light absorption and carrier transmission is completed by different material; Its biggest advantage is that it is accomplished by majority carrier transmission charge conduction, which means it does not exist minority carrier and the charge transfer complex problems in material surface recombination or carrier material in traditional solar cells. Because of the superiority, preparation process of dye-sensitized cells doesn't need so hard environment; the cost of the battery is much cheaper than conventional solar cells.

\section{Application of natural dyes in dye-sensitized solar cells}

Dye is one of the core materials of DSSC, its main function is to absorb the sun's rays, and transmit the photoelectron to guide band of $\mathrm{TiO}_{2}$, the pros and cons of the performance of the DSSC photoelectric conversion efficiency plays a decisive role. In the last 20 years, the researchers of natural dye sensitizer research focused on the chlorophyll, anthocyanins, carotenoid pigment and tannin acid etc.

Tannins and its derivatives sensitizing DSSC.Tannins and their derivatives are polyphone compounds, can occur strong complexation action with $\mathrm{Ti}^{4+}$, formatting insoluble colored compound, its absorption peak at about $560 \mathrm{~nm}$, to $\mathrm{TiO}_{2}$ electrode has good sensitization effect. As a result, the tannins can be a good sensitizer of dye-sensitized cells.

K.Tennakone, etc [6] have done a deep research on the tannic acid and its derivatives as sensitizer of the performance of dye-sensitized cells. Their tannins extracted from black tea and so on as a sensitizer, and use CuI as a solid electrolyte. The maximum short circuit current is $7 \sim 9 \mathrm{~mA} / \mathrm{m}^{2}$, and photocurrent decline rate is less than $5 \% / \mathrm{h}$ (under the sun rays simulator of $950 \mathrm{~W} / \mathrm{m}^{2}$ ). Using porous carbon instead of $\mathrm{Pt}$ as the electrode, the performance of the battery is better, the short circuit current and open circuit voltage respectively $3 \sim 4 \mathrm{~mA} / \mathrm{m}^{2}$ and $0.5 \mathrm{~V}$, the author thinks that if using other tannins kind material, optical current also increases. 
Anthocyanin and its derivatives sensitizing DSSC.Anthocyanins belong to flavonoids compounds, which is a kind of polyphenol compounds widely existing in the leaves of plants, fruits and flowers, in order to protect the plants from uv damage. Cyanine glycosides are the most common anthocyanins, red in the acid solution, has a strong absorption peak around $520 \mathrm{~nm}$. Cyanine glycosides in $\mathrm{TiO}_{2}$ adsorption on the surface of the very quickly (Fig. 2). As sensitizer of DSSC, anthocyanin dyes with high stability, high electron injection efficiency and higher sensitization efficiency and get the favor of the researchers, is one of the most studied natural dyes
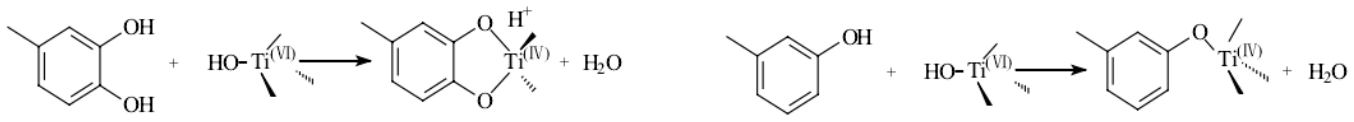

Fig. 2 Adsorption of anthocyanins to $\mathrm{TiO}_{2}$

Kumara, etc. [7] extracted the Perilla pigment from Perilla leaf, and compares the extracted from the plant leaf chlorophyll and Perilla sensitization and cooperative sensitized effect respectively. Two kinds of pigment cooperative sensitized obviously improve the conversion efficiency than single sensitizing, assembling the battery conversion efficiency of $1.3 \%$, short circuit current density of 4.8 $\mathrm{mA} / \mathrm{cm}^{2}$, open circuit voltage of $534 \mathrm{mV}$. This is the first success example of sensitization which extracted mixed dye collaborative from a single plant.

Carotenoids sensitizing DSSC.Carotenoids can combine with $\mathrm{TiO}_{2}$ electrode groups, can also serve as DSSC cell sensitizer. Frank G. Gao etc. [8] selects the ACOC (Figure 3, the ACOC molecules combine with the surface of the $\mathrm{TiO}_{2}$ is shown in Figure 4) as A sensitizer dyes, with hydroquinone solution as electrolyte solution, obtained the open circuit voltage of battery in $426 \mathrm{~nm}$, short-circuit current, the maximum power output and IPCE $0.15 \mathrm{~V}, 4.6 \mathrm{uA} / \mathrm{cm} 2,1.9 \mathrm{uW} / \mathrm{cm}^{2}$, and $34 \%$ respectively, the stability test results show that the short circuit current was reduced by $10 \%$ after $1 \mathrm{~h}$.

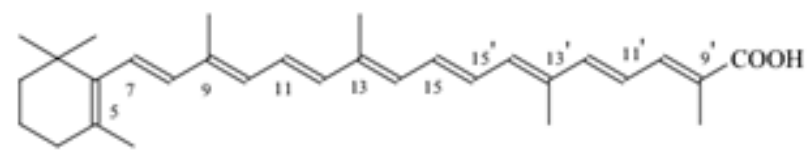

Fig. 3 Chemical formula of ACOC

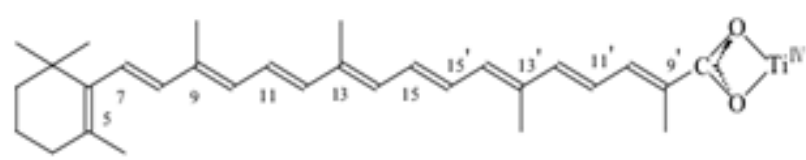

Fig. 4 Adsorption of ACOC to $\mathrm{TiO} 2$

Other natural pigment. There are other natural pigments can be used as dye sensitizers, their sort is various and its access methods are simple. Furukawa [9] extracted the red cabbage pigment from red cabbage, curcumin and Perilla pigment as dye sensitizers, they found the red cabbage pigment and curcumin cooperative sensitized when battery conversion efficiency can reach $0.6 \%$, more than any single kind of pigment. Tennakone, etc. [10] extracted of sandalwood from rosewood acid dye sensitizer, and found the battery under the simulated sunlight irradiation of $800 \mathrm{w} / \mathrm{m}^{2}$ can obtain about $6 \mathrm{~mA} / \mathrm{cm}^{2}$ of short circuit current density and the open circuit voltage of $450 \mathrm{mV}$.

\section{Conclusion}

Dye sensitized solar cell (DSSC), with its advantages of cheap, much to be approved by scientists from all over the world. Natural dye becomes a hotspot in the research of the dye-sensitized solar cells with low cost, rich variety, easy to get, and no pollution to the environment.

All in all, DSSC has low cost, simple production process. This is unmatched by other kinds of solar cells. Although there are some problems at the moment, but along with the advance of technology, its good application prospect will be apparent, and it is bound to have practical 
application certainly. This will help to solve the human energy needs, and relief increasingly prominent environmental problems owing to burning fossil fuels.

\section{References}

[1] Brian O R, Michael G. A low-cost, high-efficiency solar cell based on dye-sensitized colloidal TiO2 films[J]. Nature, 1991, 353:737-740.

[2] Michael G. The Advent of Mesoscopic Injection Solar Cells[J]. Progress in Photovoltaics: Research and applications, 2006, (14): 429-442.

[3] Neil R. Optimizing Dyes for Dye-Sensitized Solar Cells[J]. Angewandte Chemie International Edition, 2006, (45): 2338-2345.

[4] JGreg P S. Education and solar conversion: Demonstrating electron transfer[J]. Solar Energy Materials and Solar Cells, 1998, 55:157-178.

[5] Christian G G, André S P, Neyde Y M I. Photoelectrochemical solar cell using extract of Eugenia jambolana Lam as a natural sensitizer[J]. Anais da Academia Brasileira de Ciências, 2003, 75: 163-165.

[6] Tennakone K, Kumarasinghe A R, et al. Efficient photosensitization of nanocrystalline TiO2 films by tannins and related phenolic substances[J]. Journal of Photochemistry and Photobiology A: Chemistry, 1996, 94: 217-220.

[7] Kumara G R A, Kaneko S, Okuya M, et al. Shiso leaf pigments for dye-sensitized solid-state solar cell[J].Sol Energy Mater Sol Cells,2006,90(9):1220.

[8] Liska P, Thampi K R, Grätzel M, et al. Nanocrystalline dye-sensitized solar cell/copper indium gallium selenide thin-film tandem showing greater than $15 \%$ conversion efficiency[J]. Applied Physics Letters, 2006, 88: 203103.

[9] Shoji Furukawa, Hiroshi Iino, Tomohisa Iwamoto, et al. Characteristics of dye-sensitized solar cells using natural dye[J]. Thin Solid Films,2009,518(2):526

[10] Tennakone K, Kumara G R R A, Kottegoda I R M, et al. Sensitization of nano-porous films of $\mathrm{TiO} 2$ with santalin and construction of dye-sensitized solid-state photovoltaic cells[J]. J Photochem Photobiol A: Chem,1998,117:137. 